\title{
Mortality Risk of Exercise Associated Coronorary Events Compared with Those Occurring at Rest
}

\author{
Lt Col Peter Lynch, \\ MD, MRCP, RAMC \\ Cardiac Dept, Queen Elizabeth Military Hospital, Woolwich
}

SUMMARY: This paper examines the total incidence of coronary events in British Army males in a five year period and $\stackrel{\mathbb{D}}{\circ}$ shows that, whether diagnostic criteria are strict or lax, the mortality rate for coronary events occurring during strenuouses exercise is no greater than that for such events occurring at rest.

\section{Introductions}

During exercise myocardial oxygen demand is increased. Coronary artery occlusion occurring by chance at this time might be expected to be associated with an increased risk of mortality via, for example, an increase in infarct size. While anecdotes abound, the author is unaware of any work specifically orientated to this topic. The major difficulties in a study such as this are the problem of retrospective confirmation of the accuracy of the diagnosis in a large population and the completeness of recording of the patient's activity at the time of the coronary event. The quality and completeness of Army records make this study possible.

\section{Subjects and Methods}

Only British Army males were considered (thus excluding the Brigade of Gurkhas and the Women's Services) who had suffered a coronary event between 1 January 1973 and 31 December 1977. During that period strenuous activity after a coronary event was actively discouraged. There were 582 such events of which 156 were fatal. The diagnosis of a fatal coronary event was made or confirmed at post mortem in 137 cases. Of the 19 cases not so confirmed nine had clinical and electrocardiographic evidence of acute infarction at demise and a further 10 had a history of previous infarction of whom seven had chest pain as a terminal symptom. These 156 deaths were culled from the records of the medical statistics branch of the Ministry of Defence. That they were the total number of deaths in that period was confirmed by reference to the Casualty List, compiled separately by another branch of the Ministry. Examination of the medical records of these 156 deaths revealed information on the deceased's activity within six hours of demise in 98 cases $(62 \%)$. In a further 19 cases the deceased had a serious illness likely to preclude strenuous exercise (16 had a previous myocardial infarction, two occurred in the post-operative period, and one was an asthmatic on treatment). Thus in 117 cases $(75 \%)$ a clear statement could be made as to whether or not the deceased had undertaken strenuous exercise within six hours of demise. The actual number who had was 22 (Table 1).
It is, and has been, Army policy that any suspected $\overrightarrow{\vec{\omega}}$ coronary event, of whatever nature, is assessed in? hospital. No cases are treated at home. With ourg youthful population, and a high percentage of youthful, inexperienced Army doctors as general practitioners $\vec{\omega}$ and Regimental Medical Officers, it is likely that this policy was complied with fully. Nevertheless, it can becu seen that admission to hospital is inherent in t⿳亠丷厂巾 definition of a coronary event.

Table 1

Deaths from coronary heart disease in relation to strenuous exercise.

\begin{tabular}{|c|c|c|c|}
\hline No & Age & Activity & Dominant Lesion \\
\hline 1 & 25 & football & thrombotic occlusion? \\
\hline 2 & 40 & football & thrombotic occlusion \\
\hline 3 & 34. & rugby & thrombotic occlusion \\
\hline 4 & 39 & three mile run & thrombotic occlusion \\
\hline 5 & 25 & brawling & thrombotic occlusion \\
\hline 6 & 29 & climbing & thrombotic occlusion \\
\hline 7 & 35 & circuit training & thrombotic occlusion \\
\hline 8 & 35 & football & thrombotic occlusion \\
\hline 9 & 43 & training run & thrombotic occlusion \\
\hline 10 & 41 & football & atheromatous occlusion \\
\hline 11 & 35 & climbing & atheromatous occlusion \\
\hline 12 & 36 & football & severe stenosis \\
\hline 13 & 34 & three mile run & severe stenosis \\
\hline 14 & 31 & training run & severe stenosis \\
\hline 15 & 45 & running & severe stenosis \\
\hline 16 & 32 & cross country run & severe stenosis \\
\hline 17 & 37 & marching & severe stenosis \\
\hline 18 & 42 & cycling & severe stenosis \\
\hline 19 & 30 & running & severe stenosis \\
\hline 20 & 34 & rugby & moderate stenosis \\
\hline 21 & 41 & lifting weights & $\begin{array}{l}\text { necropsy data } \\
\text { not available }\end{array}$ \\
\hline 22 & 49 & tennis & necropsy not carried o \\
\hline
\end{tabular}


The number of non-fatal coronary events which occurred, and the number of patients in whom they occurred, were taken from the hospital discharge summaries received by the medical statistics department which receives reports of hospital admissions as well. These admission figures were used to assess the completeness of the discharge reporting. Hospital discharge reports are received for $89 \%$ of all hospital admissions, including those to civilian hospitals, the frequency of reporting varying with the severity of the condition and the length of stay in hospital (by reason of military exercise, billet accommodation etc, the Army admits many minor cases to hospital). Coronary Heart Disease (CHD) is not separately recorded in admission reports, being lumped under Circulatory Diseases (Chapter VI of the International Classification of Diseases, 8th revision), but the report rate for similarly serious diseases such as neoplasia, psychiatric illness, and acute apendicitis is $100 \%$.

Only cases reportedly due to CHD were investigated to ascertain the minutiae of the diagnosis. Thus no check was made on all other diagnostic categories to find cases of CHD which had been missed. The diagnosis of CHD was made in all cases by hospital physicians. 426 such episodes (non-fatal) were reported.

Such was the quality of the records that the likelihood of the physician's diagnosis being accurate could be assessed. Four categories of probability were used (Table 2). The diagnosis of myocardial infarction could be verified in 195 cases by a history of typical chest pain and unequivocal electrocardiographic evidence of acute transmural infarction in all cases. Supporting evidence (usually cardiac enzyme levels, but also in some cases

Table 2

\section{Categories of diagnostic probability of CHD in survivors.}

\begin{tabular}{lllll}
\hline Category & Diagnosis & $\begin{array}{l}\text { Associated } \\
\text { with }\end{array}$ & $\begin{array}{l}\text { Not associated } \\
\text { with }\end{array}$ & Total \\
& strenuous & strenuous & \\
& exercise & & \\
\hline
\end{tabular}

\begin{tabular}{rlrrr}
\hline 1 & Myocardial & & & \\
& infarction & 26 & 169 & 195 \\
3 & Angina & 14 & 36 & 50 \\
4 & Probable CHD & 8 & 39 & 47 \\
& Doubtful CHD & 12 & 62 & 74 \\
& Not CHD & - & - & 16 \\
& Missing data & - & - & 9 \\
& Investigative & & & 35 \\
& admissions & - & - & \\
& & & & 426
\end{tabular}

Strenuous exercise is defined as any exercise likely to induce shortness of breath in a normal individual, ie. anything more vigorous than a brisk walk on the fiat.

\section{Table 3}

Criteria for probable coronary event

$T$ wave flat or inverted in S1 lead of ECG

Inferior MI diagnosed on inferior $Q$ waves or transient $T$

change on ECG with no rise in enzymes

Transient ST elevation or depression

Positive exercise test

Left ventricular failure with past proven CHD

Left ventricular failure with CHD proven at post mortem

Ventricular tachycardia or ventricular fibrillation with previously proven myocardial infarction

Intermittent atrial fibrillation with previously proven myocardial infarction

$Q$ waves in lead $S 1$ of the ECG with elevated enzymes

Chest pains only with acute myocardial infarction two months later

Coronary bypass surgery as the only record

Equivocal ECG and elevated enzymes

ECG - Electrocardiogram

MI - Myocardial infarction

thallium scan or angiography) was also available in a but 43 cases. The typical history of angina in 50 cases was supported by a positive maximal exercise test in $15 \stackrel{\mathbb{Q}}{\Omega}$ angiography in 11, ischemic electrocardiogram in five previous infarction in eight, and subsequent infarctiom in 11. Probable CHD was diagnosed when there waso typical chest pain (typical of myocardial ischemia) with other abnormalities suggestive of $\mathrm{CHD}$ but not amounting to transmural infarction (Table 3). The criteria used to diagnose doubtful CHD are detailed in Table 4. A further 60 episodes recorded as coronary events are excluded from further discussion. These are 16 events labelled as CHD in which there were data to confirm conditions associated with, or likely to mimic, but none to incriminate CHD itself (Table 5), 35 admissions which were for further investigations and not for the coronary event, and nine cases in which the central medical file could not be obtained.

Of the 366 episodes in these four categories, 74 were second or subsequent episodes and the subjects were therefore unlikely to have been taking strenuous exercise. Of the remaining 292 in whom a single event occurred during the period of study, 23 had had a coronary event prior to this time, and these too were unlikely to have been exercising. There remain 269 , in whom a history of exercise was available in 125 and a history of rest in 95 , leaving only $49(13 \%)$ in whom no such data were available (Table 6). Of the 125 in whom a history of exercise was given, only 60 were indulging in strenuous exercise (Table 7). In the other 65 cases the patient was said to have exercise associated chest pain without the type of exercise being specified. Almost all of these fell into the angina or doubtful CHD diagnostic 
Table 4

\section{Doubtful cases of Coronary Heart Disease}

Previous infarction. Little evidence of a new event ECG changes during non-CHD illness or surgery

Chest pain unsupported by other evidence of an event Chest pain with equivocal ECG or exercise test Chest pain with positive ECG or exercise test but with negative thallium scan or angiogram Abnormal ECG only Chest pain with normal ECG but raised cardiac enzymes

outcome (30\%). Twenty-two of the fatal (Table 1) and 60 of the non-fatal (Table 7) coronary events wer $\bar{\phi}$ associated with strenuous exercise, giving a mortalitf rate for exercise-related events of $27 \%$, which is nod significantly different. When only proven transmurat infarction is considered, and assuming that all deaths. from CHD had, or would have had, transmurat infarction, then there were 156 deaths from transmur $\$$ infarction and 195 survivors, giving an overall death rat of $44 \%$. Twenty-two fatal (Table 1 ) and 26 non-fata (Table $7 \mathrm{~A}$ ) transmural infarctions were related t 8 strenuous exercise, giving an exercise associated mortality of $46 \%$.

There were 292 non-fatal events in the proven and probable categories (Table 2) giving an overall mortalit $\vec{\psi}$ for those likely to have had a coronary event as $35 \%$ (Table 8). Forty-eight of those non-fatal events wer exercise related (Table $7 \mathrm{~A}, \mathrm{~B}, \mathrm{C}$ ), giving an exercise associated mortality of $31 \%$ (Table 8 ).

\section{Discussion}

In $13 \%$ of non-fatal events an exercise history wasenof recorded. The effect of any further exercise associafed cases in this group would have been to lower mortafte from exercise associated events. Similarly, in 65 cases where the record merely stated "chest pain on exerti\$્\$ the exercise was assumed not to be strenuous. Any erop resulting from this assumption would lower exeres mortality still further. No exercise data were availablein. 39 of the 156 fatalities. A plausible reason for this is thace no connection with exercise existed. In any case is is likely that the proportion of exercise deaths in this grof was smaller than in the main group. But even if it

14. Hypertension. Diabetes. CVA. Claudication

15. Chest pain. Equivocal ECG. Positive exercise test. Hypoplastic circumflex coronary artery without atheroma.

16. Unable to pass basic fitness test.

\section{CVA - Cerebrovascular accident}

categories and carried a bald statement such as "the patient complained of chest pain on exertion", often with a remark on duration eg: "for six weeks". Under these circumstances it was thought likely that the exercise was an exaggeration of normal activity rather than strenuous. Also it was felt that the severity of exertion would influence the patient's statements and so those of the recorder. Finally, since exercise associated non-fatal events are the denominator, the use of the smaller figure ensures than any error will exaggerate the mortality rate from exercise related events.

\section{Results}

Of 582 episodes diagnosed as coronary events, 60 (all non-fatal) were excluded for reasons already explained. Of the remaining 522 coronary events, 156 had a fatal

\section{Table 6}

\section{Breakdown of activity data.}

Total events
Deaths
History of strenuous exercise
History of normal activity
History of serious illness
No exercise data available

Survivors

426

Wrong diagnosis
Investigative readmissions
No CHD data available
History of strenuous exercise
History of unspecified exercise
History of normal activity
History of previous coronary event
within the study period
History of previous coronary event
outwith the study period
No exercise data available

582 156 
Table 7

Survivors a coronary event during strenuous exercise.

\section{A. Myocardial Infarction}

\begin{tabular}{|c|c|c|}
\hline No & Age & Activity \\
\hline 1 & 33 & circuit training \\
\hline 2 & 47 & squash \\
\hline 3 & 39 & hockey \\
\hline 4 & 38 & 6-a-side football \\
\hline 5 & 31 & 12 mile route march \\
\hline 6 & 47 & walking the dog \\
\hline 7 & 34 & 3 mile run \\
\hline 8 & 43 & 3 mile run \\
\hline 9 & 42 & one mile run \\
\hline 10 & 34 & 3 mile run \\
\hline 11 & 43 & hockey \\
\hline 12 & 42 & mowing the lawn \\
\hline 13 & 36 & mountaineering \\
\hline 14 & 40 & squash \\
\hline 15 & 36 & 4 mile run \\
\hline 16 & 25 & swimming \\
\hline 17 & 41 & lifting a weight \\
\hline 18 & 43 & stoking a boiler \\
\hline 19 & 26 & 3 mile run \\
\hline 20 & 42 & moving house \\
\hline 21 & 35 & football \\
\hline 22 & 29 & 3 mile run \\
\hline 23 & 51 & golf \\
\hline 24 & 47 & tennis \\
\hline 25 & 43 & walking steep hill \\
\hline 26 & 44 & lifting boxes \\
\hline
\end{tabular}

\section{B. Angina}

\begin{tabular}{rll}
\hline No & Age & Activity \\
\hline 1 & 34 & road running \\
2 & 39 & walking uphill \\
3 & 37 & 3 mile run \\
4 & 44 & lifting boxes \\
5 & 33 & playing football \\
6 & 35 & stoking boiler \\
7 & 37 & 3 mile run \\
8 & 38 & cross country run \\
9 & 38 & coitus \\
10 & 33 & dancing \\
11 & 37 & swimming \\
12 & 49 & climbing stairs \\
13 & 41 & 40 step-ups \\
14 & 46 & walking uphill
\end{tabular}

Table 7 cont

\section{Probable CHD}

\begin{tabular}{lll}
\hline No & Age & Activity \\
\hline 1 & 33 & running \\
2 & 39 & running \\
3 & 43 & tennis \\
4 & 45 & gardening \\
5 & 36 & 5 -a-side football \\
6 & 47 & running \\
7 & 41 & gardening \\
8 & 45 & climbing stairs \\
& & \\
D. Doubtful CHD & \\
\hline No & Age & Activity \\
\hline 1 & 42 & walking uphill \\
2 & 35 & swimming \\
3 & 33 & running \\
4 & 39 & running training \\
5 & 40 & hill walking \\
6 & 28 & rugby \\
7 & 35 & 3 mile run \\
8 & 40 & marching \\
9 & 36 & walking uphill \\
10 & 43 & cycling \\
11 & 29 & one mile run \\
12 & 35 & half mile run \\
& &
\end{tabular}

Table 8

Mortality rate for coronary events

OVERALL.

STRENUOUS EXERCISE
Crude Mortality

$$
\underline{156}=27 \%
$$$$
\frac{22}{82}=27 \%
$$

Corrected Mortality

$\frac{156}{522}=30 \%$

$\frac{22}{82}=27 \%$

Mortality from proven transmural

$\frac{156}{351}=44 \%$

$\frac{22}{48}=46 \%$

infarction

Mortality from proven and probable coronary events

$$
\frac{22}{70}=31 \%
$$

the same, this would add another four deaths to the 22 already discovered and raise the exercise mortality to $30 \%$ which is identical to the overall mortality figure. Thus it can be seen that the mortality from coronary events occurring during strenuous exercise is no greater than that from those occurring at rest and this conclusion remains valid whether diagnostic criteria of a coronary event are strict or lax. 